\title{
EFFECT OF ASHWAGANDHA ON PHARMACOKINETIC AND PHARMACODYNAMIC PARAMETERS OF GLIMEPIRIDE IN STREPTOZOTOCIN-INDUCED DIABETIC RATS
}

\author{
NAGARAJ B, VEERESHAM C* \\ Department of Pharmacy, University College of Pharmaceutical Sciences, Kakatiya University, Warangal, Telangana, India. \\ Email: ciddiveeresham@yahoo.co.in
}

Received: 23 November 2017, Revised and Accepted: 03 January 2018

\begin{abstract}
Objective: The present investigation is aimed to determine the effect of ashwagandha (AG) on pharmacokinetic (PK) and pharmacodynamic (PD) parameters of glimepiride (GP) in diabetic rats. Simultaneously, the effect was also studied in normal rats.

Methods: Diabetes in rats was induced by streptozotocin. The PK parameters are calculated in normal and diabetic rats. PD studies were performed in diabetic rats only.

Results: From the PK results, 2.26-folds of improvement in the oral bioavailability of GP in normal rats were observed when treated with GP in a combination of AG and which is statistically significant ( $\mathrm{p}<0.001)$. In case of diabetic rats, the oral bioavailability (3.42-folds) of GP was significantly increased when coadministered with AG and was higher (about 33.5\%) than the normal rats. Further, the rate of clearance and also the volume of distribution significantly changed in diabetic rats. The blood glucose levels were significantly reduced in GP and AG treated (6.15\% reduction) compared to GP alone (5.45\% reduction) treated diabetic rats during a period of $24 \mathrm{~h}$ were noticed from PD studies. The maximum reduction was observed at $6 \mathrm{~h}(55.46 \%)$ when compared with standard GP treatment (46.06\%) in case of GP and AG combination treatment.
\end{abstract}

Conclusion: Therefore, the results suggestive that, the AG might be advantageous as an adjuvant to GP in an appropriate quantity, and also the dose of GP may need to be adjusted to avoid any complications.

Keywords: Glimepiride, Ashwagandha, Streptozotocin, Rats, Pharmacokinetics, Pharmacodynamics.

(C) 2018 The Authors. Published by Innovare Academic Sciences Pvt Ltd. This is an open access article under the CC BY license (http://creativecommons. org/licenses/by/4. 0/) DOI: http://dx.doi.org/10.22159/ajpcr.2018.v11i4.23960

\section{INTRODUCTION}

Diabetes mellitus (DM) is a chronic metabolic disorder characterized by high levels of blood glucose concentration hyperglycemia caused by insulin deficiency, often combined with insulin resistance [1] and alters the metabolism of lipids, carbohydrates, proteins, and increases the risk of vascular diseases. Glimepiride (GP), sulfonylurea drug and is widely used in type- 2 diabetes treatment. Its hypoglycemic action is due to the promotion of endogenous insulin secretion by pancreatic $\beta$ - cell stimulation. GP is entirely absorbed and metabolized by CYP2C9 in the liver [2].

Herbal medicines are still foremost significant of majority of the world inhabitants for primary health concern in the developing countries. Variety of herbs from the Indian medicinal plants was identified for the management of DM [3,4]. Herbal medicines used by the general population are usually complex mixture of many compounds and considered an alternative therapy for the DM [5]. Both the putative active ingredients and others constituents present in that mixture have the potential to cause both pharmacokinetic (PK) and pharmacodynamics (PD) interactions. It has been reported that herbal products/medicines, when coadministered with allopathic medicines, leads to PK and PD interactions [6].

Among these Withania somnifera is popularly known as Ashwagandha (AG) or winter cherry is one of the medicinal plants. The practitioners of traditional systems of medicines in India call it as Indian Ginseng [7]. It is widely classified as an adaptogen and shown to have wide range of activities including antidiabetic [8], antioxidant [9], hepatoprotective and antidepressant $[10,11]$, anticancer, antistress, anti-inflammatory, immunomodulatory [12], and antibacterial activity [13]. The major biochemical constituents of $W$. somnifera are steroidal alkaloids and lactones together known as withanolides [14]. Previously, Shravan et al.,2011 [15] reported the pretreatment effect of ashwagandha extract with increased transport of buspirone (CYP3A4 substrate) across rat intestine by inhibiting the transporters and enzymes across intestine (CYP 3A4). Coadministration of Withania markedly altered the plasma levels and PKs of amikacin in healthy buffalo calves [16]. Sujatha et al., 2013 [17], reported the effect of boswellic acids on the PD and PK studies of GP. Therefore, the present study was aimed at investigating the effect of AG pretreatment on PK and PD s of GP.

\section{MATERIALS AND METHODS}

\section{Materials}

GP and gliclazide (internal standard) were obtained as gifted samples from Dr. Reddy's Labs, Hyderabad, India. AG extract was gift sample from Sami Labs, Bangalore, India. Methanol (High-performance liquid chromatography [HPLC]-grade), Potassium dihydrogen orthophosphate and Orthophosphoric acid of (AR grade) were purchased from Merck Specialties Pvt. Ltd., Mumbai. Streptozotocin (STZ) was purchased from HiMedia Chemicals, Mumbai, India. Double distilled water was collected from Millipore water system (Direct-Q-UV-3). All other chemicals used were of analytical grade.

\section{Methods}

Experimental animals

Before the investigation, all the animal experiments were reviewed and approved by the Institutional Animal Ethical Committee (IEAC), UCPSc, Kakatiya University, Warangal, India (IAEC/01/UCPSC/KU/2016). Male albino Wistar rats weighing $210 \pm 30 \mathrm{~g}$ were purchased from Mahavir Enterprises, Hyderabad, India. The animals were housed in standard polypropylene cages and maintained under standard laboratory 
conditions $(12 \mathrm{~h}$ light and dark cycle; at an ambient temperature of $25 \pm 5^{\circ} \mathrm{C} ; 35-60 \%$ of relative humidity). The animals were fed with standard rat pellet diet and water ad libitum.

\section{Experimental design}

Induction of diabetes

The rats (male albino Wistar) weighing 180-250 g were overnight fasted, and diabetes was induced by injecting $55 \mathrm{mg} / \mathrm{kg}$ of STZ intraperitoneally in citrate buffer ( $\mathrm{pH} 4.5)$. After $72 \mathrm{~h}$, blood samples were collected from by retro-orbital puncture and serum was analyzed for glucose levels. Rats with blood glucose levels of $>250 \mathrm{mg} / \mathrm{dl}$ were considered as diabetic and were used for the study.

\section{PK study}

The study is conducted in normal as well as in diabetic rats. After overnight fasting, the rats were randomly divided into two groups (each group contains 6). Group I (control) was administered with GP ( $1 \mathrm{mg} / \mathrm{kg}$ body wt po) suspended in $0.01 \%$ Tween - 80 solution on $8^{\text {th }}$ day. Group II was pretreated with AG root extract $(500 \mathrm{mg} / \mathrm{kg} \mathrm{po}$ ) for 7 days and on the $8^{\text {th }}$ day treated with AG followed by GP $(1 \mathrm{mg} / \mathrm{kg})$. Blood samples of about $0.5 \mathrm{~mL}$ were collected at predetermined time intervals from retro-orbital vein puncture using heparinized capillary tubes. Serum samples were separated after centrifugation at $8000 \mathrm{rpm}$ for $15 \mathrm{~min}$ and the samples were stored in deep freezer at $-20^{\circ} \mathrm{C}$ until analysis by HPLC.

\section{HPLC analysis}

GP concentrations were estimated in serum by RP-HPLC with slight modification of the earlier reported method [18]. The analysis was performed by the ultra-fast liquid chromatography (Shimadzu, Kyoto, Japan) system with gradient capability binary pump (LC-20AD) and the analytical column $\mathrm{C}_{18}$ (2), $250 \times 4.6 \mathrm{~mm} ; 5 \mu$ particle size (Luna $5 \mu$, Phenomenex). The column effluent was monitored with UV-visible dual wavelength absorbance detector (SPD-A20) at $230 \mathrm{~nm}$. The mobile phase consisting of methanol and $10 \mathrm{mM}$ potassium dihydrogen orthophosphate (pH 3.0 adjusted with orthophosphoric acid) in the ratio $80: 20 \% \mathrm{v} / \mathrm{v}$, and delivered at a flow rate of $1.0 \mathrm{~mL} / \mathrm{min}$

\section{Extraction of GP serum samples}

To about $100 \mu \mathrm{L}$ of serum sample, added $100 \mu \mathrm{L}$ of internal standard gliclazide concentration of $25 \mu \mathrm{g} / \mathrm{mL}$ and then added $100 \mu \mathrm{L}$ of methanol as precipitating agent and vortex mixed for $1 \mathrm{~min}$, further centrifuged at $13000 \mathrm{~g}$ for $15 \mathrm{~min}$. The supernatant was transferred into a clean, similarly labeled tube and was stored at $-20^{\circ} \mathrm{C}$ until analysis. The resultant samples $20 \mu \mathrm{L}$ were injected into HPLC for analysis of GP.

\section{Calculation of PK parameters}

Noncompartmental PK analysis was performed using Phoenix WinNonlin (6.4 version). The PK parameters such as $\mathrm{C}_{\max } \cdot \mathrm{T}_{\max }, \mathrm{AUC}_{0-\mathrm{r}^{\prime}}$ $\mathrm{AUC}_{\text {total' }} \mathrm{T}_{1 / 2}, \mathrm{MRT}, \mathrm{Vd}$, and clearance were calculated.

\section{Statistical analysis}

All the PK parameters were expressed as mean \pm SD. The data were statistically evaluated using Student's unpaired t-test using GraphPad Prism 5.03.2011 Software. Values corresponding to $\mathrm{p}<0.05$ were considered as significant.

\section{PD study}

PD studies were conducted in diabetic-induced rats only. After overnight fasting, the diabetic rats were randomly divided into four groups containing six rats in each group. The treatment of rats is as follows:

- Group I: Received normal saline per orally (diabetic control group).

- Group II: Administered with GP (1 mg/kg, body weight) per orally suspended in Tween 80 solution.

- Group III: Pretreated with AG (500 mg/kg, body weight) per orally suspended in normal saline.
- Group IV: Pretreated with AG (500 mg/kg, body weight) per orally suspended in normal saline for 7 days and on the $8^{\text {th }}$ day AG followed by GP $(1 \mathrm{mg} / \mathrm{kg})$ after a gap of $5 \mathrm{~min}$.

Blood samples were withdrawn from the retro-orbital plexus of the rats at "0" (Initial fasting blood sample), 2, 4, 6, 8, 12, and $24 \mathrm{~h}$ after the treatment. The samples were analyzed for blood glucose using glucose oxidase-peroxidase method. The mean blood glucose levels and percentage reduction in blood glucose levels were determined and applied to statistical treatment.

\section{RESULTS AND DISCUSSION}

The diabetes in rats was induced by streptozotocin. During the induction, the weight of the rats was reduced. The rats with more than $250 \mathrm{mg} / \mathrm{dL}$ of glucose level were considered as is diabetic and used for the studies.

\section{PK study in normal and STZ-induced diabetic rats}

The PK studies were conducted in normal and diabetic-induced rats. The mean serum concentration and time profiles of GP and GP with AG were showed in Figs. 1 and 2. The PK parameters also represented in Tables 1 and 2 . From the results, $C_{\max }, \mathrm{AUC}_{0-\infty}, \mathrm{T}_{1 / 2}$, and MRT in normal rats were $8.03 \pm 0.29$ and $14.35 \pm 0.50 \mu \mathrm{g} / \mathrm{mL}$; $26.89 \pm 3.21$ and $60.97 \pm 1.77 \mu \mathrm{g} . \mathrm{h} / \mathrm{mL} ; 2.02 \pm 0.19$ and $3.08 \pm 0.09 \mathrm{~h}$; $3.54 \pm 0.22$ and $5.07 \pm 1.35 \mathrm{~h}$, respectively, for GP and GP plus AG treated normal rats and were statistically $(\mathrm{p}<0.05)$ increased to $1.78,2.26$, 1.52 and 1.43-times, respectively. In case of clearance and volume of distribution, there was 0.44 and 0.67 -times decreased levels were observed, respectively.

In case of diabetic rats, $\mathrm{C}_{\text {max }}, \mathrm{AUC}_{0-\infty}, \mathrm{T}_{1 / 2}$, and MRT were increased by $2.13,1.95,1.35$, and 1.20 -folds, respectively, and whereas the clearance and volume of distribution were decreased by 0.51 and 0.69 -times, respectively, in GP and GP + AG treatment. However, the $\mathrm{T}_{\max }$ in both normal and diabetic rats was found to be $2 \mathrm{~h}$. This indicates that the

Table 1: PK parameters of GP in different groups of normal rats (mean $\pm S D, n=6)$

\begin{tabular}{lll}
\hline PK parameters & GP & GP+AG \\
\hline $\mathrm{C}_{\text {max }}(\mu \mathrm{g} / \mathrm{mL})$ & $8.03 \pm 0.29$ & $14.35 \pm 0.50^{* *}$ \\
$\mathrm{~T}_{\max }(\mathrm{h})$ & 2.00 & 2.00 \\
$\mathrm{AUC}_{0-\mathrm{t}}(\mu \mathrm{g} \cdot \mathrm{h} / \mathrm{mL})$ & $26.41 \pm 2.95$ & $60.70 \pm 1.68^{* *}$ \\
$\mathrm{AUC}_{\mathrm{tot}}(\mu \mathrm{g} . \mathrm{h} / \mathrm{mL})$ & $26.89 \pm 3.21$ & $60.97 \pm 1.77^{* *}$ \\
$\mathrm{~T}_{1 / 2}(\mathrm{~h})$ & $2.02 \pm 0.19$ & $3.08 \pm 0.09^{* *}$ \\
$\mathrm{CL} / \mathrm{F}(\mathrm{mL} / \mathrm{h} / \mathrm{kg})$ & $37.19 \pm 2.24$ & $16.40 \pm 0.06^{* *}$ \\
$\mathrm{Vd} / \mathrm{F}(\mathrm{mL} / \mathrm{kg})$ & $108.42 \pm 4.31$ & $72.91 \pm 4.12^{* *}$ \\
$\mathrm{MRT}(\mathrm{h})$ & $3.54 \pm 0.22$ & $5.07 \pm 1.35^{* *}$ \\
$\mathrm{Kel}\left(\mathrm{h}^{-1}\right)$ & $0.34 \pm 0.01$ & $0.22 \pm 0.05$ \\
\hline${ }^{*} \mathrm{p}<0.05,{ }^{* *} \mathrm{p}<0.01$ considered as significant when compared with $\mathrm{GP}$ control.
\end{tabular}

GP: Glimepiride, AG: Ashwagandha, PK: Pharmacokinetic

Table 2: PK parameters of GP in different groups of diabetic rats (mean $\pm S D, n=6$ )

\begin{tabular}{lll}
\hline PK parameters & GP & GP+AG \\
\hline $\mathrm{C}_{\max }(\mu \mathrm{g} / \mathrm{mL})$ & $10.15 \pm 0.72$ & $21.67 \pm 1.77^{* *}$ \\
$\mathrm{~T}_{\max }(\mathrm{h})$ & 2.00 & 2.00 \\
$\mathrm{AUC}_{0-\mathrm{t}}(\mu \mathrm{g} \cdot \mathrm{h} / \mathrm{mL})$ & $46.29 \pm 3.31$ & $93.24 \pm 5.05^{* *}$ \\
$\mathrm{AUC}_{\text {tot }}(\mu \mathrm{g} \cdot \mathrm{h} / \mathrm{mL})$ & $47.8 \pm 1.74$ & $163.62 \pm 3.19^{* *}$ \\
$\mathrm{~T}_{1 / 2}(\mathrm{~h})$ & $2.13 \pm 0.0 .44$ & $2.89 \pm 0.16^{*}$ \\
$\mathrm{CL} / \mathrm{F}(\mathrm{mL} / \mathrm{h} / \mathrm{kg})$ & $20.92 \pm 2.24$ & $10.68 \pm 0.06^{* *}$ \\
$\mathrm{Vd} / \mathrm{F}(\mathrm{mL} / \mathrm{kg})$ & $64.26 \pm 4.31$ & $44.6 \pm 4.12^{* *}$ \\
$\mathrm{MRT}(\mathrm{h})$ & $4.01 \pm 0.47$ & $4.82 \pm 0.15^{* *}$ \\
$\mathrm{Kel}\left(\mathrm{h}^{-1}\right)$ & $0.33 \pm 0.01$ & $0.24 \pm 0.05$ \\
\hline
\end{tabular}

${ }^{*} \mathrm{p}<0.05, * * \mathrm{p}<0.01$ considered as significant when compared with Glimepiride control. GP: Glimepiride, AG: Ashwagandha, PK: Pharmacokinetic 


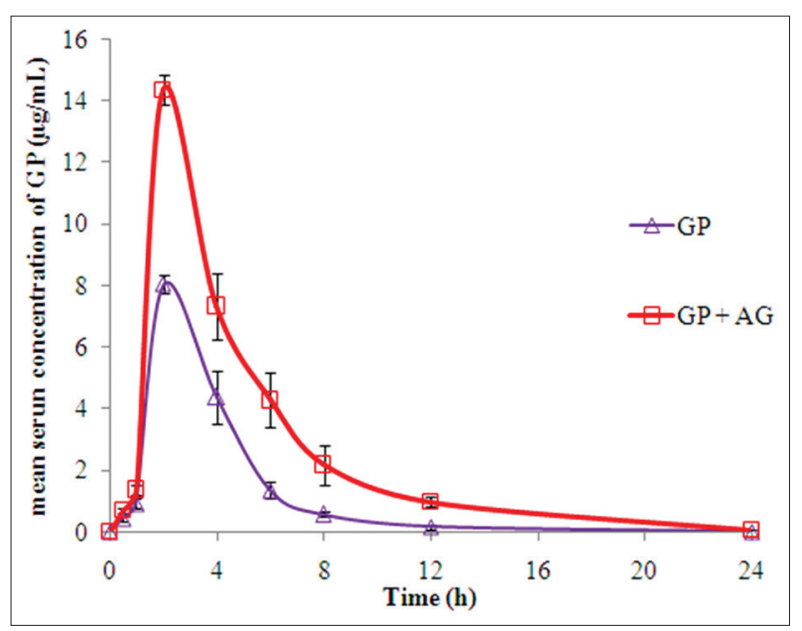

Fig. 1: Mean serum concentration of glimepiride (GP) in normal rats after oral administration of GP and GP with ashwagandha treatment (mean $\pm S D, n=6)$

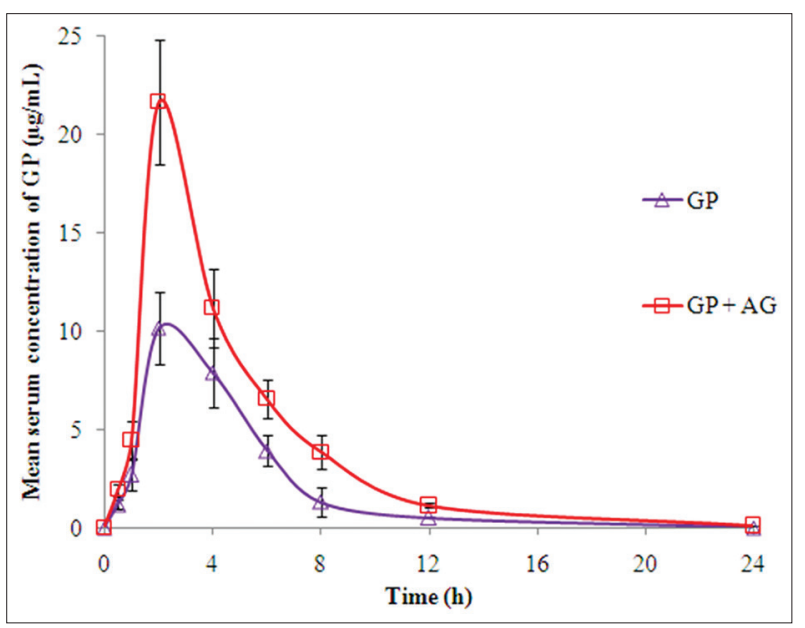

Fig. 2: Mean serum concentration of glimepiride (GP) in diabetic rats after oral administration of GP and GP with ashwagandha treatment (mean $\pm S D, n=6)$

coadministration of AG does not alter the absorption of the GP. In comparison to normal rats, there was $33.5 \%$ increment in the oral bioavailability of GP in diabetic rats when pretreatment with AG.

The variation in PK parameters $\mathrm{C}_{\text {max }}, \mathrm{AUC}_{0-\infty}, \mathrm{T}_{1 / 2}$, and MRT may be due to inhibition of drug metabolizing enzyme CYP2C9 in the liver microsomes. These results also correlate with the previous results of Sujatha et al., 2013. As per their studies, the bioavailability of GP was enhanced in the presence of boswellic acid in STZ-induced diabetic rats by altering the liver microsomal enzymes. In another study, LI et al., 2012 [19] was observed the hepatic protein expression of CYP2C9 was decreased in diabetic rats which lead to the slower clearance of glibenclamide in diabetic rats. Similar reports were also observed in the different group of researchers [20-22].

\section{PD study in diabetic rats}

In PD study, the mean serum glucose levels were determined using glucose oxidase-peroxidase method, and the percent glucose reduction at each time point was compared with $0 \mathrm{~h}$ (initial) mean glucose levels. The glucose levels of the study were shown in Table 3. The maximum percent reduction of serum glucose levels in combination with GP and AG was found to be at $6 \mathrm{~h}(55.46 \%)$ when compared with standard GP treatment (46.06\%) at $6 \mathrm{~h}$, which is statistically significant.

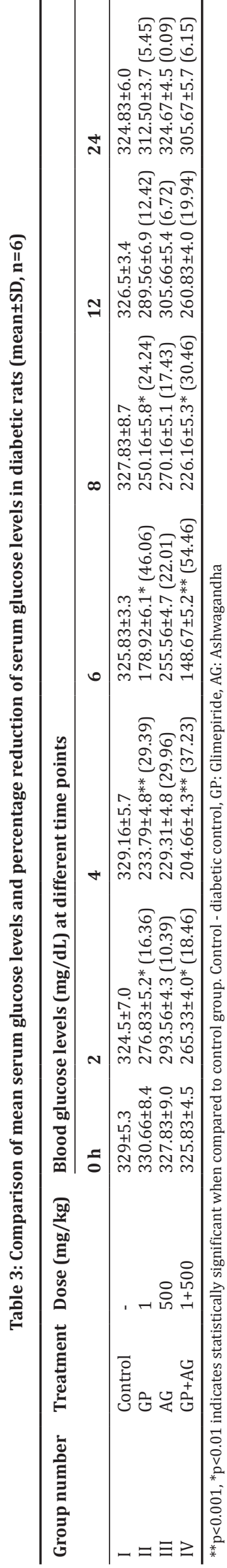


Maximum hypoglycemic activity (29.96\% reduction) was observed at $4 \mathrm{~h}$ in AG-treated group. The increased hypoglycemic activity with coadministration of GP and AG when compared with alone drug/AG treated groups suggested that enhanced glucose reduction activity of GP in diabetic rats was only with pretreatment of AG.

\section{CONCLUSION}

The effect of AG on PK and PD studies was studied. The AG significantly enhances the oral bioavailability of GP, when coadministered. The effect of AG synergistically increased in streptozotocin-induced diabetic rats when compared to normal rats. The blood glucose levels also significantly reduced when pretreated with AG than GP alone treated diabetic rats. The effect of the AG might be due to the inhibition of drug metabolizing enzyme CYP2C9 in the liver microsomes. Hence, the combination has a beneficial result in diabetic condition, it requires additional studies to confirm the applicability of herb-drug interaction in humans and conclude the mechanisms concerned.

\section{ACKNOWLEDGMENTS}

The author would like to thank Dr. Reddy's Labs, Hyderabad, India, for providing the drug sample as gift to conduct the research.

\section{AUTHORS CONTRIBUTION}

Nagaraj B - Primary author as well as investigator. Veeresham C Corresponding author.

\section{CONFLICTS OF INTERESTS}

The authors report that there was no conflict of interest, while writing the manuscript.

\section{REFERENCES}

1. Rang HP, Dale MM, Ritter JM, Moore PK. Text Book of Pharmacology. Vol. 5. New York: Churchill Livingstone; 2005. p. 666-7.

2. Rosskamp R, Wernicke-Panten K, Draeger E. Clinical profile of the novel sulphonylurea glimepiride. Diabetes Res Clin Pract 1996;31 Suppl: S33-42.

3. Manisha M, Priyanjali D, Jayant L, Saroj G, Thomas AD. Drugs used for the treatment of diabetes. J Clin Biochem Nutr 2007:40:163-73.

4. Shivraj N, Chandrashekar M. Pharmacodynamic and pharmacokinetic drug interaction of glimepiride and irbesartan in animal models. Int $\mathrm{J}$ Phytopharmacol 2013;4:174-8.

5. Dey L, Anoja SA, Yuan CS. Alternative therapies for Type 2 diabetes. Altern Med Rev 2002; 7:45-58

6. Brazier NC, Levine MA. Drug-herb interaction among commonly used conventional medicines: A compendium for health care professionals. Am J Ther 2003;10:163-9.

7. Weiner MA, Weiner J. Ashwagandha (India ginseng). In: Herbs that Heal. Mill Valley, CA: Quantum Books; 1994. p. 70-2.

8. Bhattacharya SK, Satyan KS, Chakrabarti A. Effect of trasina, an ayurvedic herbal formulation, on pancreatic islet superoxide dismutase activity in hyperglycaemic rats. Indian J Exp Biol 1997;35:297-9

9. Dhuley JN. Effect of ashwagandha on lipid peroxidation in stressinduced animals. J Ethnopharmacol 1998;60:173-8.

10. Bhattacharya A, Ramanathan M, Ghosal S, Bhattacharya SK. Effect of Withania somnifera glycowithanolides on iron-induced hepatotoxicity in rats. Phytother Res 2000;14:568-70.

11. Bhattacharya SK, Bhattacharya A, Sairam K, Ghosal S. Anxiolyticantidepressant activity of Withania somnifera glycowithanolides: An experimental study. Phytomedicine 2000;7:463-9.

12. Naidu PS, Singh A, Kulkarni SK. Effect of Withania somnifera root extract on reserpine-induced orofacial dyskinesia and cognitive dysfunction. Phytother Res 2006;20:140-6.

13. Owais M, Sharad KS, Shehbaz A, Saleemuddin M. Antibacterial efficacy of Withania somnifera (ashwagandha) an indigenous medicinal plant against experimental murine salmonellosis. Phytomedicine 2005; 12:229-35

14. Matsuda H, Murakami T, Kishi A, Yoshikawa M. Structures of withanosides I, II, III, IV, V, VI and VII new withanolide glycosides from the roots of Indian Withania somnifera D and inhibitory activity for tachyphylaxis to clonidine in isolated guineapig ileum. Bioorg Med Chem 2001;96:1499-507.

15. Shravan KY, Adukondalu D, Vamshi VY, Bhargavilatha A, Sarangapani M. Effect of ashwagandha and Aloe vera pretreatment on intestinal transport of buspirone across rat intestine. Lat Am J Pharm 2011;30:1005-9.

16. Dahikar PR, Kumar N, Sahni YP. Effect of Withania somnifera (Ashwagandha) on the pharmacokinetics of amikacin: A future antimicrobial polypharmacy. J Drug Metab Toxicol 2013;4:1-6.

17. Sujatha S, Veeresham C. Enhanced bioavailability of glimepiride in the presence of boswellic acids in streptozotocin-induced diabetic rat model. Nat Prod Chem Res 2013;1:1-6.

18. Sujatha S, Rani TS, Veeresham C. Determination of glimepiride in rat serum by RP-HPLC method. Am J Anal Chem 2011;2:160-5.

19. Li Y, Wei Y, Zhang F, Wang D, Wu X. Changes in the pharmacokinetics of glibenclamide in rats with streptozotocin-induced diabetes mellitus. Acta Pharm Sinica B 2012;2:198-204.

20. Kumar KE, Rani PD, Ram KR, Swathi P, Gupta MN. Pharmacodynamic and pharmacokinetic drug interaction of gliclazide and risperidone in animal models. Int J Pharm Pharm Sci 2012;4:659-60.

21. Babu PR, Vanishree S, Sujatha S, Kumar KK. Effect of carvedilol on the pharmacokinetics and pharmacodynamics of glipizide. Int J Pharm Pharm Sci 2012;4:133-8.

22. Jaideep S, Samir CP. Pharmacokinetic changes of fluvoxamine and pioglitazone by drug drug interaction in healthy, diabetic and depressive rats. Int J Pharm Pharm Sci 2013;5:352-5. 